\title{
Estrategias, actores, promesas y temores en las campañas de vacunación antivariolosa en México: del Porfiriato a la Posrevolución (1880-1940)
}

\author{
Strategies, actors, promises and fears \\ in the smallpox vaccinations campaigns in Mexico: \\ from the Porfiriato to the Post-revolution (1880-1940)
}

Claudia Agostoni ${ }^{1}$

\begin{abstract}
The article examines some of the strategies employed by the Mexican health authorities that led to the organization of massive and obligatory smallpox vaccination campaigns from the late 1880s to the 1940s, a period of Mexican history that corresponds to the Porfirio Diaz regime (1877-1911), to the armed phase of the Mexican Revolution (1910-1920), and to the first two decades of the Post-revolutionary governments (1920-1940). Attention will be placed of the vaccination programs in the main urban settings, notably in Mexico City, as well as the gradual but decisive organization and regulation of vaccination campaigns in the heterogeneous rural milieu. Furthermore, the importance that hygienic education acquired will be explored, as well as the divergent and contested responses that emerged due to the obligatory vaccination campaigns, responses that included resistance, fear, uncertainty and widespread acceptance.
\end{abstract}

Key words Vaccination, Vaccination brigades, Hygienic education, Fear, Hope
${ }^{1}$ Instituto de

Investigaciones Históricas, Universidad Nacional Autónoma de México. Circuito Maestro Mario de la Cueva, Zona Cultural, Ciudad Universitaria, CP 04150. México DF.

México.

agostoni@servidor.unam.mx
Resumen El artículo estudia algunas de las estrategias a las que recurrieron las autoridades de salud durante la puesta en marcha de programas vacunación antivariolosa durante los años de 1880 a 1940, periodo que corresponde al gobierno encabezado por Porfirio Díaz (1877-1911), a la fase armada de la Revolución Mexicana (1910-1920), y a las dos primeras décadas del estado posrevolucionario (1920-1940). Por una parte se prestará atención a la preeminencia que tuvo la vacunación en los centros urbanos, notablemente en la ciudad de México; y por la otra, se destacará la gradual, pero decisiva, organización y reglamentación de la vacunación antivariolosa en los programas destinados para el heterogéneo y desigual ámbito rural. Asimismo, se analizará la importancia que adquirió la educación higiénica, y se prestará atención a las divergentes respuestas que la aplicación masiva y cotidiana de la vacuna suscitó en las ciudades principales y en pequeños pueblos y municipios rurales, respuestas que incluyeron la resistencia, el temor, la incredulidad y la franca aceptación.

Palabras clave Vacunación, Brigadas de vacunación, Educación higiénica, Miedo, Esperanza 


\section{Introducción}

La viruela fue un acompañante inseparable del acontecer histórico de la Nueva España desde el momento mismo de la conquista española durante el siglo XVI. A lo largo del periodo colonial (1521-1821) y durante el transcurso de la primera centuria de México como nación independiente, la viruela provocó la muerte de infinidad de personas, dio lugar a numerosas crónicas y descripciones implacables de la tragedia, y alimentó el clima de inseguridad, rumor, huida y soledad que en momentos de emergencia epidémica se imponen entre amplios y muy diversos sectores socia$\operatorname{les}^{1-3}$. La viruela, descrita por diversos observadores como sinónimo de miseria, muerte y desolación, llevó a que las autoridades civiles y eclesiásticas procuraran contener su propagación con la imposición de rígidos cordones para mantener en aislamiento forzoso a los enfermos, además de encenderse hogueras en las calles para limpiar el aire de las impurezas que se decía favorecían la propagación de esa enfermedad. La viruela, fue una de las enfermedades más conocidas entre amplios sectores sociales por las cicatrices que dejaba en el rostro de los supervivientes, señal clara y visible de su frecuente paso y propagación. La diseminación de esa enfermedad también alentó que la población recurriera a las purgas, dietas y sangrías; a las imploraciones individuales y colectivas, así como a las penitencias públicas y a los rituales privados para evitar enfermar.

Entre 1795 y 1799, cuando una epidemia de viruela afectó a la mayor parte de la Nueva España, las autoridades procuraron extender lo más posible la práctica de la variolización, consistente en la introducción de la secreción de las pústulas virulentas de una persona enferma en otra aparentemente sana. La variolización, conocida desde siglos atrás por médicos asiáticos y africanos, se extendió durante el siglo XVIII en diferentes naciones europeas. En la Nueva España, ante el avance incontenible de la viruela en la ciudad de México en 1797, el Virrey Marqués de Branciforte (1794-1798) promulgó un edicto que determinó la utilidad de la variolización, dándose inicio a un programa formal de variolización auspiciado por las autoridades civiles y eclesiásticas, programa que se reiteró era de carácter voluntario ${ }^{4}$. Participaron en éste, las llamadas Juntas de Sanidad, el Arzobispo Alonso Núñez de Haro, el Real Tribunal del Protomedicato, los ayuntamientos y las autoridades secundarias, así como diversos médicos ilustrados, entre éstos, José Ignacio Bartolache. Asimismo, fueron enviadas a diferentes ciudades del reino instrucciones para la variolización, entre las que destaca el folleto titulado: Método claro, sencillo y fácil para practicar la inoculación de viruelas, elaborado por el Real Tribunal del Protomedicato ${ }^{5,6}$. Las ventajas y peligros de la variolización fueron temáticas debatidas en la Nueva España durante los años finales del siglo XVIII, discusiones que coincidieron con la amplia difusión que durante esos mismos años recibieron los escritos y hallazgos de Edward Jenner en Inglaterra. Jenner, en su escrito An inquiry into the causes and effects of the variolae vaccinae $(1798)^{7,8}$, anunció un método novedoso y distinto al de la variolización: la inoculación con el virus de la viruela bovina (cowpox), provocando con ello reacciones inmunitarias eficaces contra el de la viruela.

La introducción formal de la vacuna jenneriana a la Nueva España ocurrió en 1804 con la llegada de la Real Expedición Filantrópica de la Vacuna dirigida por Francisco Xavier de Balmis ${ }^{9,10}$. A partir de ese momento inició un capítulo de la historia de larga duración en aras de la contención, control y posterior erradicación de la viruela en México, y cuyo sustento fue la vacunación. Numerosos fueron los legados de la Real Expedición Filantrópica de la Vacuna. En 1804 se instaló en la ciudad de México la Oficina Conservadora de la Vacuna que funcionó a lo largo del siglo; diferentes estados de la república crearon oficinas de vacuna y casas de vacunación y tanto las autoridades sanitarias como las civiles y eclesiásticas, procuraron capacitar a un personal médico y no médico para la adecuada y eficaz aplicación del recurso salvador, así como informar al público en general acerca de las virtudes, bondades y beneficios de la vacuna.

No obstante, a lo largo del siglo XIX la vacuna y su aplicación, fueron también sinónimos de dificultad, penuria, escasez y temor ${ }^{11-14}$. El inestable acontecer político y económico del país y las constantes guerras civiles e intervenciones extranjeras obstaculizaron la continuidad y sistematización de los esfuerzos para contener la propagación de la viruela. Además, la conservación y adecuada aplicación, primero de la vacuna de brazo a brazo, y a partir de 1919 de la vacuna humanizada, así como la frecuente negativa y resistencia del público para recibirla, fueron importantes retos a vencer para generaciones de funcionarios sanitarios y médicos diplomados.

El objetivo del presente trabajo consiste en analizar algunas de las estrategias a las que recurrieron las autoridades de salud en la organización y puesta en marcha de las campañas de vacunación 
antivariolosa entre las décadas finales del siglo XIX y la década de los 1940, así como destacar algunas de las principales dificultades a las que se enfrentaron tanto en las ciudades principales, como en pequeños pueblos y municipios rurales. Se subrayará que los programas obligatorios de vacunación generaron reacciones y respuestas encontradas entre el público y el personal de salud en cuyas manos recayó la obligación de vacunar; respuestas que incluyeron la resistencia, el temor, la incredulidad y la franca aceptación.

Aunado a lo anterior, se examinará por qué los programas de vacunación se sustentaron en un vasto programa de educación higiénica, y se subrayará que tanto la educación y persuasión fueron incapaces de desvanecer viejos y arraigados temores en torno a la vacuna: miedo a contraer la enfermedad u otros padecimientos por la deliberada introducción en el organismo de una sustancia ajena al cuerpo humano; temor al sufrimiento o al dolor producto de la vacunación, o bien temor por parte de los vacunadores ante el rechazo, resistencia y negativa de la población. En suma, se destacará que las respuestas y reacciones encontradas por parte del público en general y que acompañaron a las campañas de vacunación en México durante los años de 1880 a 1940, lejos de desvanecerse, permanecieron como elementos constitutivos de las mismas.

\section{Las promesas de la vacuna contra la viruela: del Porfiriato a la Posrevolución}

Durante el largo gobierno encabezado por el General Porfirio Díaz (1877-1910), cuyos lemas fueron "orden y progreso", tanto la unificación y cohesión política, como el fortalecimiento institucional y económico fueron progresivamente posibles después de décadas en las que predominó la inestabilidad, las guerras internas y las intervenciones extranjeras. El gobierno de Díaz, caracterizado por la insistencia en reiterar que el país requería de un gobierno fuerte, con la capacidad de fomentar un desarrollo económico sostenido y de reformar a la sociedad, otorgó una enorme importancia a la pública salubridad. Ciudades como las de México, Guadalajara, Puebla, San Luis Potosí y Monterrey rebasaron los límites que durante siglos les habían contenido, y la población del país aumentó a un ritmo acelerado. En 1877 el país contaba con nueve millones de habitantes; en 1895 la cifra se ubicaba en 13 millones, pasando a poco más de 15 millones de personas en 1910. Sin embargo, la mayor parte de la población del país radicaba en pequeñas poblaciones rurales: pueblos, haciendas o ranchos carentes de las comodidades de la vida moderna y de la presencia de las instituciones y actores del ámbito de la salud pública estatal.

Un elemento fundamental del proyecto modernizador del régimen de Díaz fue transformar al país en una nación que reflejara el progreso, la prosperidad y la modernidad, y en la que sus habitantes devinieran en ciudadanos trabajadores, morales, sanos y vigorosos. Para ello, y como parte del vasto proyecto de modernización de la época, se expidieron reglamentos y códigos penales y de salud, se construyeron importantes obras de infraestructura sanitaria, caminos y líneas férreas, y se impulsó una lucha contra la suciedad, el desaseo y la insalubridad. En esa lucha destacó la contención de enfermedades endémicas y epidémicas. De acuerdo con el Consejo Superior de Salubridad (CSS) - la máxima autoridad sanitaria desde 1841 -, la contención de la viruela mediante la aplicación de la vacuna humanizada o de brazo a brazo era uno de los principales objetivos a alcanzar. La vacuna tenía en el país casi un siglo de historia, y la viruela, además de ser endémica, con frecuencia tenía manifestaciones epidémicas ${ }^{15,16}$.

En la opinión del médico Domingo Orvañanos, autor del Ensayo de geografía médica (1899), tan sólo durante la década de 1880 se habían registrado más de veinte epidemias de viruela en los estados de Chiapas, Durango, Guerrero, Hidalgo, México, Oaxaca, Puebla, San Luis Potosí, Sinaloa, Sonora, Veracruz, Zacatecas, así como en el Distrito Federal y en la ciudad de México. Orvañanos - al igual que otros médicos de la época - consideraba que la viruela era una enfermedad que produce la muerte muy frecuentemente, que a veces origina la pérdida de la vista y que siempre produce cicatrices que desfiguran la fisionomía de las personas. Como los peligros del contagio de la viruela son numerosos e imposibles muchas veces de evitar, es de suma importancia para nosotros recibir el beneficio de la vacuna ${ }^{17}$. Ante la posibilidad de morir, de perder el sentido de la vista, o frente a la deformidad que provocaba si se llegaba a sobrevivir la enfermedad ${ }^{18}$, el Consejo Superior de Salubridad determinó que era necesario garantizar que la aplicación de la vacuna fuese realizada adecuadamente por médicos competentes, argumentando que únicamente una formación médica permitiría resolver todas las cuestiones referentes a la vacunación, y muy particularmente en lo tocante a si la vacuna era falsa o legítima. 
En mayo de 1882 el Ministerio de Gobernación dio a conocer un dictamen de la Comisión de Epidemiología del Consejo Superior de Salubridad. El dictamen asentó que los servicios públicos de vacuna carecían de una sólida organización a nivel nacional y que la vacuna con frecuencia era aplicada por personas que desconocían los métodos adecuados para vacunar ${ }^{19}$. Por tanto, el Ministerio de Gobernación solicitó a lo diferentes estados de la república organizar servicios eficaces de vacunación y envió a las autoridades estatales una "Instrucción sobre la vacuna" para disipar cualquier duda en torno a su adecuada e higiénica aplicación. Aunado a lo anterior, el Consejo Superior de Salubridad - bajo la dirección del médico Eduardo Liceaga - reiteró la necesidad de organizar programas de educación higiénica para fomentar la aceptación entre el público del recurso salvador, recurriéndose simultáneamente a la fuerza y la coerción, como ha sido analizado en recientes investigaciones históricas ${ }^{20}$.

Siete años después, es decir en 1889, una epidemia de viruela afectó a la mayor parte del país, prolongándose durante más de un año y causando la muerte de 40,000 personas ${ }^{21}$. Ante la ausencia de coordinación y sistematización de los esfuerzos para contener la propagación de la viruela durante momentos de emergencia epidémica, en 1900 el Consejo Superior de Salubridad estableció en la capital la Oficina Central de Vacuna para conservar y distribuir la vacuna de "brazo a brazo" a la mayor parte de los estados que carecían de oficinas conservadoras de vacuna. Por otra parte, y en lo que concierne a la obligatoriedad de vacuna, ésta se decretó en 1903 haciéndose efectiva la disposición legal en la ciudad de México, así como en los estados de Chiapas, Chihuahua, Durango, Estado de México, Michoacán, Morelos, Tepic, Yucatán y Zacatecas, entre otros. Sin embargo, es preciso destacar que el marco legal de la Constitución Política de los Estados Unidos Mexicanos de 1857 - respetuoso de las soberanías estatales - impidió el diseño y la aplicación de una misma política de salubridad en todo el país. Por ende, no todos los estados de la república decretaron o pusieron en marcha programas obligatorios de vacunación sino hasta la década de los 1920.

Durante el régimen de Díaz también fueron frecuentes las discusiones entre los médicos, las autoridades y el público en general en torno a los beneficios y los peligros de la vacuna humanizada y de la vacuna animal, debates que emergieron a partir de 1868 cuando el médico Ángel Iglesias buscó promover en el país la aplicación de la vacuna animal. En 1866 Iglesias introdujo a México el virus bovino procedente de Francia, mismo que utilizó para inocular terneras y cuyos resultados presentó ante la Sociedad Médica de México en 1868. En su trabajo - intitulado "Memoria sobre la vacuna animal"11 - anunció que México finalmente contaba con la vacuna animal y destacó que sus investigaciones, sustentadas en las de diversos médicos franceses, finalmente harían cesar las "inquietudes legítimas" en torno a la vacuna, en particular las referentes a la transmisión de la sífilis.

Entre 1868 y los años iniciales del siglo XX en México, los médicos y funcionarios públicos que se manifestaban en contra del empleo de la vacuna animal reiteraban que se trataba de un procedimiento incierto; que su eficacia era cuestionable y que el procedimiento tenía un costo monetario mucho mayor que el que significaba conservar y aplicar la vacuna de brazo a brazo. Además, argumentaban que si la vacuna de brazo a brazo proporcionaba los mismos beneficios que la vacuna animal, no había razón suficiente para optar por un procedimiento más costoso. Por otra parte, los adherentes y defensores de la vacuna animal reiteraban que con ésta cesaría la propagación de enfermedades como la sífilis; destacaban que en México la escasez de vacuníferos y la resistencia de las madres para que sus hijos portaran la vacuna de brazo a brazo eran serías limitaciones para la contención de la viruela, limitaciones que únicamente podrían superarse con el empleo de la vacuna animal ${ }^{22,23}$. En este sentido, y al finalizar la década de 1880, el médico Domingo Orvañanos consideraba que en México era necesario recurrir a la vacuna animal debido a que confería mayor protección contra la viruela que la vacuna de brazo a brazo; dado que facilitaría la revacunación y a que sería más fácil la obtención de grandes cantidades del virus vacuno para la protección de un mayor número de personas ${ }^{24}$. En 1907, y argumentando a favor de la vacuna animal, el médico R. E. Manuell señalaba que los servicios públicos de vacuna requerían emplear ese recurso debido a "que no expone como la de brazo a brazo al peligro posible de servir de medio de transmisión de la sífilis" ${ }^{25}$. Los debates y la incertidumbre en torno a la vacuna animal, así como la larga historia que en el país tenía la aplicación de la vacuna de brazo a brazo, llevaron a que durante el largo gobierno de Porfirio Díaz se recurriera a ambos recursos preventivos, una situación que solamente cambio a partir de 1919 , cuando se proscribió la vacuna de brazo a brazo. 
La fase armada de la Revolución Mexicana (1910-1920) fue una década de significativos cambios políticos, sociales, económicos y culturales que llevaron a la destrucción del estado porfiriano y a la enunciación y defensa de amplias demandas políticas, sociales y agrarias. Durante esos años, el constante movimiento de tropas y civiles, la violencia, la insalubridad, el hambre y la carestía, así como la imposibilidad por parte de las autoridades de salud de aplicar la vacuna, incidió a que en los estados de Aguascalientes, San Luis Potosí, Tabasco, Tamaulipas, Veracruz, Yucatán, así como en el Distrito Federal, se registraran brotes epidémicos de viruela, tifo, fiebre amarilla e influenza ${ }^{26}$. La rápida y al parecer incontenible diseminación de esas enfermedades fue ampliamente comentada y debatida en 1918, durante el V Congreso Médico Nacional que tuvo lugar en la ciudad de Puebla. Los participantes del Congreso, funcionarios del recién creado Departamento de Salubridad Pública (DSP, 19171943), en sustitución de su antecesor, el Consejo Superior de Salubridad, representantes de las autoridades sanitarias de los estados, así como un nutrido grupo de médicos, coincidieron en afirmar que la viruela no podía permanecer presente en el panorama sanitario nacional. De acuerdo con el médico Joaquín Baeza Alzaga, la viruela proseguía causando la muerte, la ceguera y la deformidad de los mexicanos. Destacó que la vacuna tenía un siglo de historia en el país, y que por tanto era imprescindible organizar un servicio de vacuna eficaz a nivel nacional; instruir a los médicos y a las enfermeras cómo aplicarla de manera adecuada e higiénica, y sobre todo, reiteró que era necesario informar al público sobre los múltiples beneficios que recibirían al aceptar la vacuna voluntariamente ${ }^{27}$. Por otra parte, el médico José Ruiz expresó durante el mismo Congreso que en el país predominaba una "verdadera aberración” a la vacuna, aberración que en su opinión era más tenaz entre "la gente de nuestro bajo pueblo", cuyas principales víctimas eran los niños ${ }^{28}$. Por ende, Ruiz asentaba que era indispensable impulsar una vasta campaña de educación higiénica. La educación era considerada como sustento inseparable del éxito de la vacunación, pero también, la educación fue uno de los pilares del estado posrevolucionario mexicano que nació hacia 1920 y cuyo lema principal fue la reconstrucción nacional.

De acuerdo con los gobiernos posrevolucionarios entre 1920 y 1940, la reconstrucción del nuevo estado exigía de una tenaz y constante vigilancia de la salud o ausencia de salud de am- plios sectores sociales considerados como en riesgo - en particular los pobres, la infancia y la mujer embarazada; de la educación, vigor y fortaleza de los mexicanos, y claro está, de la prevención de enfermedades evitables como la viruela ${ }^{29}$. Por tanto, y como señalaba el doctor Jesús Monjarás, la intervención del estado era impostergable ante la ignorancia del pueblo y por la apatía de amplios sectores sociales frente a la diseminación de la viruela ${ }^{30}$.

Correspondió al Departamento de Salubridad Pública organizar los primeros programas de inmunización masivos, sistemáticos y obligatorios a nivel federal. El impulso de lo anterior obedeció a que la Constitución Política de los Estados Unidos Mexicanos de 1917 determinó que las disposiciones del DSP eran obligatorias en todo el país, que tenían un carácter ejecutivo y que el DSP pasaría a depender directamente del poder ejecutivo. En nombre de esa legalidad, el estado posrevolucionario por vez primera en la historia nacional emprendió campañas de vacunación, de erradicación de plagas, de higienización urbana y rural a lo largo y ancho del país ${ }^{31}$. Asimismo, la Constitución de 1917 determinó que en caso o amenaza de una epidemia, el DSP estaba facultado para emitir las medidas preventivas que considerara pertinentes en todo el territorio nacional. En este sentido, y apelando a una terminología bélica, el médico Alfonso R. Ochoa señalaba que las enfermedades nos atacan despiadadas, el combate es cuerpo a cuerpo; cada quien debe poner en juego cuantos recursos tenga a su alcance... ${ }^{32}$. Uno de los recursos que requerían ser impuestos era la vacuna contra la viruela. No obstante las promesas, las virtudes y la esperanza que encerraba la vacuna - anunciadas desde el ocaso del siglo XVIII y a lo largo del siglo XIX - se mostraban incapaces de terminar con el temor, la incredulidad y el rechazo que la simple mención de la palabra "vacuna" provocaba entre amplios sectores sociales.

\section{Estrategias de vacunación: reglamentación, educación y persuasión}

De acuerdo con el gobierno posrevolucionario y las autoridades de salud pública estatal al despuntar la década de los 1920, la vacuna requería ser sinónimo de confianza, seguridad y esperanza y su aplicación convertirse en una práctica obligatoria, masiva y cotidiana. Una importante medida en este sentido tuvo lugar en 1919, cuando se determinó que únicamente la vacuna ela- 
borada con linfa vacunal de ternera preparada con pulpa emulsionada con glicerina podría ser aplicada. Por tratarse de un recurso que evitaría la transmisión de enfermedades como la sífilis y el tétanos, y debido a que su producción y distribución facilitaría su masiva aplicación, tanto el Instituto Bacteriológico Nacional (hasta 1921), como el Instituto de Higiene, se abocaron a la producción de la misma. Tan sólo en 1923 el Instituto de Higiene produjo más de 3 millones de dosis vacunales ${ }^{33}$. La cifra denota la prioridad que tuvo la contención de la viruela y refleja que la inmunización de la población se considero como un elemento que contribuiría a afianzar un clima de seguridad y certidumbre en el país que poco a poco dejaba atrás la violencia revolucionaria. Cabe mencionar que en 1928 el Instituto de Higiene se abocó a la producción de sueros antidiftérico, antitetánico y antiescarlatinoso; tuberculina; toxinas diftérica y escarlatinosa para inmunizaciones activas; antitoxina diftérica y vacunas antivariolosa, antirrábica y pertusis.

El entusiasmo y la confianza de las autoridades de salud en la vacuna antivariolosa ocupó los espacios públicos y privados de la ciudad de México durante la celebración del primer "Día de la Vacuna”, el 27 de septiembre de 1923. El Día de la Vacuna, que formó parte de las actividades de la Semana de Salubridad, buscó dar a conocer las virtudes de la vacuna y aplicarla al mayor número de capitalinos, además de informar al público en general sobre las consecuencias que sobrevendrían en la niñez no vacunada. Durante ese día, se realizó una intensa campaña de propaganda a favor de la vacuna, reiterándose que los padres de familia tenían la responsabilidad de vacunar a sus hijos para evitarles el dolor, la deformidad, la ceguera o la muerte prematura. Las autoridades de salud, apelando a la responsabilidad moral y paternal, así como a descripciones implacables de la niñez no protegida, asentaban que únicamente con la vacuna los padres podrían evitar desgracias y futuros remordimientos $^{34}$. Así, en las calles, avenidas, plazas y mercados de la ciudad se distribuyeron hojas sueltas e informativas para que la población acudiese a los centros permanentes e itinerantes de vacunación instalados en diversos puntos de la capital ${ }^{35}$. Tan solo durante el Día de la Vacuna recibieron el recurso preventivo por vez primera 3,801 personas, además de revacunarse a 4,258 individuos ${ }^{36}$.

La promesa de calma, seguridad y salud que encerraba la vacuna antivariólica llevó a que en marzo de 1925 se expidiera el "Reglamento impreso sobre la vacunación y revacunación de la viruela en México”. Éste determinó que la vacuna era obligatoria e incuestionable, señalándose que sería absurdo esperar los destrozos del mal para atacarlo, en vez de prevenir. Un argumento reiterado en el Reglamento de 1925 era que la viruela proseguía en el panorama sanitario nacional debido a la ignorancia y ausencia de una cultura higiénica entre los mexicanos. Debido a lo anterior, se estableció que no existía justificación alguna para negarse a recibir la vacuna, y que la vacunación sistemática era el único recurso que garantizaría que el Estado cumpliera con sus principales responsabilidades: la defensa de los habitantes y la salud y bienestar de la colectividad ${ }^{37}$. Por ende, a partir de 1925 se decretó la obligatoriedad de la vacuna en los recién nacidos, adultos y ancianos. Únicamente las personas que contaran con un certificado de vacunación quedaban exentas. Los inmigrantes al entrar al país estaban obligados a recibir la vacuna al no presentar el certificado correspondiente, además de establecerse que todas las personas serían revacunadas después de cinco años de haber recibido la primera vacuna. El reglamento también contempló las sanciones: arresto de 36 a 48 horas, o hasta acceder a ser vacunado ${ }^{38}$.

La esperanza depositada en la aplicación sistemática, obligatoria y cotidiana de la vacuna llevó a que el Código Sanitario de los Estados Unidos Mexicanos de 1926, así como el promulgado en 1934, se reiterara su obligatoriedad a nivel federal. El Código de 1926, el primero de la posrevolución y nutrido de una terminología bélica, subrayó que para el combate de la enfermedad era imprescindible identificar, separar y tratar a los grupos o sectores sociales considerados como en riesgo de contraer y/o de propagar enfermedades infecto contagiosas; destacó que la vacuna era obligatoria en todos los niños menores de cuatro meses; que los adultos que no la hubiesen recibido requerían hacerlo y que la revacunación era igualmente obligatoria ${ }^{39}$. Además, para contener o prevenir brotes de viruela y de otras enfermedades infecciosas, los médicos titulados y debidamente registrados ante las autoridades tenían la obligación de dar aviso de cualquier caso confirmado o bien, de cualquier sospecha sobre la presencia de personas con enfermedades transmisibles a las autoridades. Asimismo, estableció que los directores de hospitales, escuelas, fábricas y talleres, así como cualquier otra persona que tuviese conocimiento de alguna persona o grupo de personas portadora de alguna enfermedad transmisible, requería notificarlo al Departamento de Salubridad. Aunado a lo anterior la ley determinó 
que los directores de las escuelas oficiales y particulares de la federación tenían la obligación de vigilar que sus subalternos, empleados o educandos, se vacunaran o revacunaran ${ }^{40}$.

La transformación y profundización legislativa en el ámbito de la salubridad fue particularmente destacada durante el transcurso de la década de los 1930. En 1935, el jefe del Departamento de Salubridad Pública, el médico y general José Siurob, dio a conocer un nuevo "Reglamento sobre vacunación y revacunación antivariolosa” y las campañas de vacunación antivariolosa adquirieron una magnitud no vista hasta ese momento. El objetivo: llevar y aplicar la vacuna hasta el último confín de la república. Por ende, se estableció que toda localidad carente de servicios médicos o de servicios permanentes de vacuna serían cubiertas por Brigadas de Vacunación que serían enviadas para tal efecto, autorizándose a las mismas recurrir a cualquier medio que consideraran necesario para realizar sus labores ${ }^{41}$. También se estableció que los oficiales del registro civil de todo el país tenían la obligación de exigir el certificado de vacunación antivariolosa para inscribir los nacimientos, y que el certificado también sería solicitado por las instancias eclesiásticas antes de celebrar los bautismos católicos o cualquier otra ceremonia religiosa ${ }^{42}$. Es preciso destacar que entre 1935 y 1945 las campañas de vacunación antivariolosa adoptaron dos modalidades. Las campañas de emergencia y las de fondo. Las primeras se organizaron en las regiones donde la viruela presentaba características epidémicas, mientras que las segundas, tuvieron por objetivo localizar y extinguir los focos e inmunizar a la población susceptible. Sin embargo, para el éxito de ambas modalidades se determinó que era necesario seguir al pie de la letra los planes específicos previamente formulados, movilizando a un personal debidamente preparado (epidemiólogos, personal vacunador, lectores de vacuna); dotar a las brigadas de linfa antivariolosa en suficiente cantidad y calidad, además de especificarse que cualquier caso notificado como viruela requería ser constatado y confirmado mediante un diagnóstico médico ${ }^{43}$.

La insistencia de las autoridades de salud para aplicar de manera obligatoria, masiva y cotidiana la vacuna antivariolosa a nivel nacional despertó viejos temores e intensificó los rumores: temor llano y simple a la enfermedad, pero también temor a su cura: a recibir o a aplicar la vacuna. El temor y la incertidumbre del público no eran del todo injustificados: temor ante la posibilidad de enfermar al recibir vacunas contaminadas; temor a que la vacuna no funcionara; o bien, incertidumbre e incredulidad ante la pre- sencia de los agentes de vacunación, hombres y mujeres ajenos y extraños a las comunidades a las que llegaban con la consigna de vacunar a como diera lugar. Asimismo, el temor se incrementaba cuando el público tenía conocimiento de niños vacunados que entraban en shock o que tenían convulsiones después de ser inmunizados. La vacuna también podía ser fatal: por la contaminación del virus vacunal o cuando se vacunaba a una persona cuyo sistema inmunológico se encontraba extremadamente debilitado. Frente a la posibilidad de enfermar de viruela, pero también ante la vacuna y los agentes de vacunación, el miedo fue acompañante inseparable de las campañas de vacunación.

\section{Entre el deber, la esperanza y el temor: brigadas y agentes de vacunación}

A partir de la década de 1920 la organización y reglamentación de la vacunación sistemática de la población llevó a que se multiplicaran los centros y oficinas permanentes e itinerantes que ofrecían el servicio a lo largo del país. El Departamento de Salubridad Pública dotó gratuitamente linfa vacunal de ternera a las oficinas y centros de vacuna de los estados, así como a los médicos diplomados que la solicitaran para aplicarla en sus consultorios privados. Tan sólo en la ciudad de México funcionaban las Oficinas de Vacuna Fernando Malanco, Doctor Iglesias, Doctor Jenner, Doctor Balmis, Doctor Luis Muñoz y la Doctor Miguel Muñoz, así como diez Oficinas Foráneas de Vacunación creadas en 1922. El servicio también se ofrecía de manera gratuita en las iglesias, como en el Sagrario Metropolitano; en diversos templos protestantes ${ }^{44}$, así como en los Centros de Higiene Infantil, verdaderas clínicas de atención materno-infantil que se erigieron en las colonias más pobres y densamente pobladas de la capital entre 1922 y $1927^{45}$.

Las labores de vacunación cobraron una muy particular intensidad durante la celebración de festividades religiosas, como por ejemplo los días 12 de diciembre cuando se celebra a la Virgen de Guadalupe. Al iniciar el mes de diciembre de 1931, y ante la inminente llegada de miles de peregrinos a la ciudad de México por motivo de la festividad religiosa, las autoridades de salud organizaron una campaña extraordinaria de vacunación. El Departamento de Salubridad Pública consideraba que los miles de peregrinos que ingresarían a la ciudad procedentes de muy diversas regiones del país podrían ser portadores de un sinnúme- 
ro de enfermedades infecciosas. Frente a ello, el Departamento de Salubridad Pública instaló tres carpas equipadas con el personal, mobiliario e instrumental requerido para vacunar en las inmediaciones de la celebración. Durante quince días los agentes de vacuna aplicaron la linfa vacunal de ternera a un promedio de entre 200 y 400 personas diariamente (en dos turnos), con y sin el consentimiento de los peregrinos, además de canalizar a todo enfermo de viruela, varicela y lepra a los hospitales al margen de la oposición ${ }^{46}$.

El que la viruela pudiera adquirir proporciones epidémicas era un rumor que también era alimentado cotidianamente por la prensa, que daba a conocer información día tras día referente al avance de la enfermedad. Debido a ello, se intensificaron los trabajos de las Brigadas Ambulantes de Vacunación en las principales ciudades. Éstas estaban conformadas por estudiantes de medicina, enfermeras tituladas y por agentes de vacunación, quienes recorrían los barrios, las colonias y las vecindades de los centros urbanos más poblados a bordo de automóviles o en camiones buscando cualquier indicio, sospecha, rumor o certeza de casos de viruela. Las Brigadas, también se presentaban sorpresivamente en los talleres, en las fábricas y en las escuelas, en los mercados y en las inmediaciones de las iglesias.

En algunas ocasiones la aproximación de las Brigadas desató rechazo y temor. En los meses de abril y mayo de 1923, el DSP registró un aumento considerable en el número de casos de viruela en la capital. Ante el avance de la enfermedad, se determinó que se procedería a vacunar por focos. Es decir, después de recibir aviso de que en una casa o habitación se encontraba un enfermo de viruela, los vacunadores de las Brigadas procederían a vacunar a todos los habitantes de esa casa, a los de las casas vecinas y a los de cuatro manzanas a la redonda. En junio de 1923 las Brigadas concentraron sus actividades en dos focos que de acuerdo con las autoridades representaban un peligro inminente para la salud de la colectividad: el primero en el barrio de Tepito y el segundo en las calles de Santa Cruz Acatitla, dos de las regiones de mayor marginación y pobreza de la ciudad de México en las que sus habitantes moraban en casas de vecindad en las que el hacinamiento y la insalubridad eran la norma y no la excepción.

La presencia de los vacunadores, el cerco impuesto a los habitantes y la aplicación de la vacuna en portadores o no de la enfermedad, desató escenas de pánico en las vecindades. De acuerdo con el periódico El Universal, el temor se generalizó cuando la portera de una casa de vecindad ubicada en el Barrio de Tepito anunció a gritos que se aproximaban los "hombres del lancetazo". La crónica periodística señalaba que la "muchedumbre desparecía" como tragada por la tierra y que las personas abandonaban sus labores y se escondían. Un agente de la Brigada en el barrio de Tepito - y quien solicitó el anonimato -, relató al periódico que a más de mil personas habían tenido que sacar de sus escondites y que en más de cuatro ocasiones se habían tenido que enfrentar con “valientes' quienes ante la lanceta de la vacuna respondían a puñaladas ${ }^{47}$. Como se puede apreciar, el temor a la "lanceta" estaba presente no sólo entre las personas que recibirían la vacuna, sino también entre los médicos y las enfermeras, quienes decían que se jugaban la vida "a cambio de dar un certero lancetazo en el brazo de algún mugroso" 48 .

Las autoridades sanitarias también recibían informes de los vacunadores en los que denunciaban que los directores de diversos planteles educativos se negaban a permitirles el ingreso a las escuelas por el temor que su presencia suscitaba entre los niños y sus padres ${ }^{49}$. Además, las Oficinas de Vacuna con frecuencia exigían a las autoridades de la ciudad de México el envió de policías para evitar problemas con las personas que eran conducidas a recibir la vacuna y que se negaban a recibirla ${ }^{50}$.

La esperanza depositada en la vacuna antivariolosa por parte de las autoridades de salud llevó a que durante el transcurso de las décadas de 1930 y 1940 se ampliara el radio de acción de las Brigadas de Vacunación a numerosas áreas rurales. Para ello, fueron de primera importancia los primeros convenios de coordinación entre los servicios sanitarios federales y locales de 1932; la ley de 1934 de Coordinación y Cooperación de Servicios de Salubridad entre el Departamento de Salubridad Pública y los gobiernos de los Estados; el funcionamiento a partir de 1936 de los Servicios Médicos Ejidales, así como la creación en 1937 de la Oficina de Higiene Rural y Medicina Social. Esas instancias y disposiciones buscaron organizar servicios médicos en las zonas campesinas ${ }^{51}$, extender la acción sanitaria estatal a los más apartados rincones del país, sanear el campo y fomentar la higiene rural, así como llevar la vacuna a todos los pueblos, rancherías y comunidades rurales ${ }^{52}$. Durante las décadas de 1930 y 1940 los estados de Guerrero, Hidalgo, Michoacán, Morelos, Oaxaca, Puebla, Tlaxcala y Zacatecas, entre otros, fueron recorridos por las brigadas de vacunación, integradas por un médico en jefe y por un número variable de practicantes, enfermeras o enfer- 
meros de acuerdo con el número de casos de viruela o de brotes epidémicos registrados por las autoridades. Tan sólo entre septiembre de 1935 y el mismo mes de 1936, las brigadas aplicaron 6 millones de dosis de vacuna antivariolosa a lo largo del país, siendo que en la mayor parte de los casos se trató de primovacunaciones ${ }^{53}$.

Es pertinente mencionar que algunas brigadas de vacunación fueron conformadas exclusivamente por mujeres, como en el caso del personal de la Brigada número 1 que recorrió la Cuenca de Tepalcatepec en el estado de Michoacán en 1947, y que también se reclutó y capacitó a un personal local. Para ello, representantes de las autoridades municipales, maestros, estudiantes y miembros de las organizaciones campesinas recibían un adiestramiento de 12 días, y al concluir la capacitación se integraban a las labores de las brigadas de vacunación. La anterior fue una medida de gran trascendencia, dado que con ello se buscó dejar en las localidades rurales a un personal local con los conocimientos requeridos para que vacunación gozara de continuidad.

Un elemento constante en las labores de las brigadas fue la incertidumbre. Después de prolongados recorridos, pernoctando en jacales o en escuelas, o bien en campamentos improvisados, llegaban a localidades que desconocían; se enfrentaban a la cautela o renuencia de los pobladores quienes se escondían en sus sembradíos, o quienes optaban por emigrar a las comunidades más cercanas huyendo de la vacuna. En ocasiones los vacunadores también se afrontaban a la agresión de los pobladores, motivo que llevó a que diversas brigadas de vacunación solicitaran el resguardo de soldados, o bien, a que optaran por desempeñar sus labores armados ${ }^{54}$. Precisamente por ello, fue fundamental el trabajo que simultáneamente desempeñaron las Brigadas de Educación Higiénica Rural, dependientes del Servicio de Educación Higiénica del DSP. A éstas les correspondió dictar conferencias y charlas informativas en escuelas, casas, centros de trabajo, plazas y mercados; distribuir propaganda sobre las campañas de vacunación antivariólica, contra la fiebre tifoidea y la tos ferina, así como otorgar atención médica gratuita a los campesinos indigentes. En ocasiones, las Brigadas de Educación Higiénica Rural asumieron la responsabilidad de las campañas de inmunización, tal y como aconteció en 1936 con la Brigada de Educación que fue enviada al estado de Hidalgo.

Tres recursos novedosos en los programas de inmunización en el ámbito rural mexicano fueron el cine, el trabajo de los intermediarios indígenas locales y la participación de los maestros rurales durante el transcurso de las décadas de 1930 y 1940. En este sentido, una brigada de educación higiénica rural enviada al estado de Michoacán en 1948 recurrió a las tres estrategias antes mencionadas simultáneamente en los pueblos indígenas de la región de Uruapan y Capapan. La brigada de educación higiénica, con el apoyo de los representantes de las comunidades indígenas locales, solicitó que los llamados "cancioneros" dieran a conocer las bondades y virtudes de la vacuna por medio de canciones en la lengua indígena local, el tarasco. Una vez reunidos los pobladores de las comunidades rurales, la brigada procedió a proyectar películas al aire libre y en locales cerrados, además de invitarse a los maestros rurales a participar en las tareas de convencimiento y persuasión. Entre algunas de las películas proyectadas estaban las que siguen: Viruela, Tifoidea, Qué es una enfermedad, o bien, la elaborada por Walt Disney e intitulada Defensa contra la invasión. Por lo general, la proyección de esas y de otras películas, precedían a la vacunación ${ }^{55}$. Asimismo, tanto las brigadas de educación higiénica como las de vacunación, realizaban una amplia distribución de folletos, volantes y hojas sueltas entre los maestros rurales para con ello alentar la aceptación de la vacuna.

El éxito de los programas de vacunación en el medio rural de acuerdo con las autoridades de salud descansaba en la educación higiénica, y en la colaboración de las brigadas con los maestros rurales, las autoridades locales y con los representantes de las comunidades indígenas y campesinas. Esa colaboración entre muy diversos agentes y actores era esencial sobre todo debido a que el país predominaba siendo un ámbito mayoritariamente rural; carente de caminos o de vías de acceso que mantenían en incomunicación a diversas comunidades rurales. Asimismo, fueron grandes las dificultades para preservar la vacuna con hielo (no fue sino hasta 1950 cuando se comenzó a utilizar la vacuna con linfa lanolinaza, al iniciar los trabajos de la Dirección General de la Campaña contra la Viruela en cooperación con la Oficina Sanitaria Panamericana, bajo la dirección del Dr. Carlos Calderón), debido a que su traslado se realizaba en camiones de carga, animales o a pie. Aunado a lo anterior, los vacunadores en muy diversas ocasiones se enfrentaron a la desconfianza, negativa y agresión de los habitantes.

En este sentido durante el mes de agosto de 1947 el periódico El Informador de Guadalajara, estado de Jalisco, dio a conocer a su público lector que los vacunadores que habían sido envia- 
dos a las municipalidades de Arandas y San Diego de Alejandría se enfrentaban a dificultades cotidianas. Los líderes de esas municipalidades instaban a las poblaciones indígenas a no aceptar la vacuna, arguyendo que si lo hacían, fallecerían a las veinticuatro horas de recibirla ${ }^{56}$. Por otra parte, en junio de 1948 en una comunidad rural en el estado de México, nueve soldados federales que auxiliaban a una brigada de vacunadores fueron linchados por los pobladores. Ante la violencia, la prensa local señalaba que el pueblo - calificado de "ignorante" - se había enfurecido por la presencia de los vacunadores y soldados que pretendían salvarles del $\mathrm{mal}^{57}$. Un año después, en junio de 1949 el Dr. Francisco Chavarria Velasco - Jefe de la Brigada de Vacunación 2 en el estado de Michoacán - relató que el poblado de San Antonio, al que calificó como "rebelde", el convencimiento, la persuasión, la educación higiénica y el esfuerzo de los vacunadores habían sido francamente inútiles. Los habitantes se habían levantado y se negaban a recibir la vacuna. Ante la negativa y la violencia, y debido a que peligraba la vida del personal de salud, el jefe de la brigada suspendió temporalmente las labores. Únicamente fue posible reanudarlas cuando obtuvieron el apoyo del cura del pueblo, quien desde el púlpito instó a los pobladores a aceptar la vacuna ${ }^{58}$. Dar a conocer las virtudes de la vacuna, para con ello lograr la aceptación de la protección invisible que generaba la vacuna, como se puede apreciar, rebasó por mucho el ámbito de la salubridad y formó parte esencial de los programas educativos y persuasivos desempeñados por muy diversos intermediarios culturales y actores sociales.

\section{Consideraciones finales}

La aplicación sistemática de la vacuna antivariolosa en México devino en una práctica cotidiana durante las décadas finales del siglo XIX, y en particular, durante el largo gobierno del general Porfirio Díaz. Sin embargo, la aplicación de la vacuna de brazo a brazo era una práctica que se concentraba de manera primordial en los centros urbanos del país y únicamente fue a partir de la década de los 1920, cuando se buscó extender la aplicación de la vacuna animal al desigual y heterogéneo ámbito rural. La ampliación y organización de programas sistemáticos de vacunación fue un elemento fundamental de las transformaciones por las que atravesó el país durante el proceso revolucionario y posrevolucionario; cuando la restricción del número de infectados y el control de cualquier posible foco de contagio figuraron entre los principales objetivos del nuevo estado. Sin embargo, la aceptación de la vacuna, o bien, vacunar, no estuvieron exentos de miedo y temor.

Es importante mencionar que las cifras de mortalidad por viruela declinaron de manera pronunciada y constante a partir de la década de 1920, y que el 16 de junio de 1952 el entonces presidente de la república, Miguel Alemán Valdés, declaró que la viruela había sido erradicada del panorama sanitario nacional ${ }^{59}$. Si bien se trató de una lucha secular contra la diseminación de esa enfermedad, la historia de la vacuna en México desde sus primeros momentos, durante los albores del siglo XIX y hasta la década de los 1950, estuvo marcada tanto por el temor como por la esperanza y el beneplácito. Por ende, la aplicación sistemática y cotidiana de la vacuna y la resistencia invisible que provocaba, no disipó la persistencia del temor a enfermar, el temor a vacunar, como tampoco, el temor a ser vacunado. Vacuna, esperanza y temor no se pueden deslindar. 


\section{Agradecimientos}

Agradezco el apoyo que recibí del Proyecto PAPIIT de la Dirección General de Asuntos del Personal Académico de la Universidad Nacional Autónoma de México. Una versión preliminar de este trabajo apareció en Los miedos en la historia, coordinado por Elisa Speckman Guerra, Claudia Agostoni y Pilar Gonzalbo Aizpuru (México: ElColegio de México; 2009. p. 149-173).

\section{Referencias}

1. McCaa R. Spanish and Nahuatl views on smallpox and demographic catastrophe in Mexico. Journal of Interdisciplinary History 1995; 25(3):397-431.

2. Crosby AW. Conquistador y pestilencia: the first New World pandemic and the fall of the Great Indian Empires. The Hispanic American Historical Review 1967; 47(3):321-337.

3. Gibson C. Los aztecas bajo el dominio español (15191810). México: Siglo XXI; 1977.

4. Rodriguez de Romo AC. Inoculación, economía y estética: tres dilemas en la lucha contra la viruela. In: Rodríguez ME, Martínez-Barbosa X, coordinadoras. Medicina novohispana - siglo XVIII. Historia General de la Medicina en México. Mexico: UNAM; 2001, tomo IV. p. 357-364.

5. Fernández del Castillo F. Los viajes de Don Francisco Xavier de Balmis. México: Sociedad Médica Hispano Mexicana; 2003. p. 49-53.

6. Cooper D. Epidemic disease in Mexico City, 17161813: an administrative, social and medical study. Austin: University of Texas Press; 1965.

7. Jenner E. An inquiry into the causes and effects of the Variolae Vaccinae. London: Sampson Low; 1798.

8. Bermúdez S. Trabajos académicos. La vida y obra de Jenner. Gaceta Médica de México 1946; 5:297-310.

9. Fernández del Castillo F. Los viajes de Don Francisco Xavier de Balmis. México: Sociedad Médica Hispano Mexicana; 2003.

10. Mark C, Rigau-Pérez J. The World's First Immunization Campaign: The Spanish Smallpox Expedition, 1803-1813. Bull Hist Med 2009; 83:63-94.

11. Cramussel C. La lucha contra la viruela en Chihuahua durante el siglo XIX. Relaciones 2008; 114(29):101-132.

12. Thompson AT. To save the children: smallpox inoculation, vaccination, and public health in Guanajuato, Mexico, 1797-1840. The Americas 1993; 49(4):431-455.

13. Oliver Sánchez L. La epidemia de viruela de 1830 en Guadalajara. Relaciones 2008; 114(29):77-99.

14. Bolaños MV. La inmunización contra la viruela en el Estado de México. Documentos de Investigación 2000; 4:3-13.

15. Agostoni C. Monuments of progress: modernization and public health in Mexico City, 1876-1910. Calgary: University of Calgary Press; 2003.

16. Carrillo AM. Economía, política y salud pública en el México porfiriano, 1876-1910. Historia, Ciencias, Saúde - Manguinhos 2002; 9(Supl.):67-87.

17. Orvañanos D. Tercera parte. Principales enfermedades que se observan en la república - fiebres eruptivas - viruela. Ensayo de geografía médica y climatología de la república mexicana. México: Oficina Tipográfica de la Secretaría de Fomento; 1889.

18. Orvañanos D. Ensayo de geografía médica y climatología de la república mexicana. México: Oficina Tipográfica de la Secretaría de Fomento; 1889.

19. México. Secretaría de Estado y del Despacho de Gobernación - Sección 1a. Circular. Dictamen de la Comisión de Epidemiología del Consejo Superior de Salubridad 1882; 31 mayo.

20. Carrillo AM. Los difíciles camiños de la campaña antivariolosa en México. Ciencias 1999; 55-56:18-25. 
21. Carrillo AM. Los difíciles camiños de la campaña antivariolosa en México. Ciencias 1999; 55-56:20.

22. Iglesias Á. Memoria sobre la vacuna animal. Gaceta Médica de México 1868; III(2):188.

23. Manuell RE. Higiene: el asunto de la vacuna en México. Gaceta Médica de México 1907; 3:271-281.

24. Orvañanos D. Ensayo de geografía médica y climatología de la república mexicana. México: Oficina Tipográfica de la Secretaría de Fomento; 1889.

25. Manuell RE. Higiene: el asunto de la vacuna en México. Gaceta Médica de México 1907; 3:281.

26. Barbachano EA. Desde la Independencia (1821) hasta la erradicación. In: Florescano E, Malvido E, compiladores. Ensayos sobre la historia de las epidemias en México. México: Instituto Mexicano del Seguro Social; 1992. tomo 2. p. 545-550.

27. Baeza AJ. Un medio que debe ponerse en práctica para la extinción de la viruela en la república mexicana. Memoria del V Congreso Médico Mexicano Puebla de Zaragoza, enero 9-16, 1918. México: Dirección de Talleres Gráficos; 1920. p. 270-279.

28. Ruiz J. Causas de la ceguera en México. Memoria del Congreso Médico Mexicano - Puebla de Zaragoza enero 9-16, 1918. México: Dirección de Talleres Gráficos; 1920

29. Agostoni C. Historia de un escándalo: campañas y resistencia contra la difteria y la escarlatina en la ciudad de México, 1926-1927. In: Agostoni C, coordinadora. Curar, sanar y educar: salud, enfermedad y sociedad en México, siglos XIX-XX. México: IIHUNAM/BUAP; 2008. p. 287-311.

30. Monjarás JE. Acción social en la salubridad y la higiene. Gaceta Médica de México 1929; 60:119-122.

31. Aréchiga CE. Educación, propaganda o "dictadura sanitaria”: estrategias discursivas de higiene y salubridad públicas en el México posrevolucionario, 1917-1945. Estudios de Historia Moderna y Contemporánea de México 2007; 33:66-67.

32. Ochoa AR. Un nuevo esfuerzo en pro de la higiene. Gaceta Médica de México 1923; LV:673-675.

33. Izquierdo JJ. Labores de la lección de vacuna antivariolosa del Instituto de Higiene en el año de 1923. Gaceta Médica de México 1926; 56:38.

34. Semana de Salubridad: utilidad de la vacuna. El Universal 1923; sept 27; p. 7.

35. Semana de Salubridad: utilidad de la vacuna. El Universal 1923; sept 27. p. 1; 7.

36. Vacunación contra viruela a niños escolares, empleados de comercios y federales. AHSS. Fondo: Salubridad Pública; Sección: Inspección de Vacuna, caja 4, exp. 2, f. 27.

37. Reglamento impreso sobre la vacunación y revacunación de la viruela en México; 27 marzo 1925.

38. Reglamento impreso sobre la vacunación y revacunación de la viruela en México; 27 marzo 1925. AHSSA. Fondo: Salubridad Pública; Sección: Servicio Jurídico, v. 2, expediente 9, fecha 1921-1925.

39. Mexico. Departamento de Salubridad Pública. Código Sanitario de los Estados Unidos Mexicanos. México: Imp. Manuel León Sánchez; 1926.

40. Mexico. Departamento de Salubridad Pública. Diario Oficial de la Federación 1926; tomo XXXIX.

41. Expediente relativo al Reglamento sobre Vacunación y Revacunación Antivariolosa. 1935; AHSSA. Fondo: Salubridad Pública; Sección: Servicio Jurídico, v. 42, exp. 18, 1935, foja 4.
42. Expediente relativo al Reglamento sobre Vacunación y Revacunación Antivariolosa. 1935; AHSSA. Fondo: Salubridad Pública; Sección: Servicio Jurídico, v. 42, exp. 18, 1935, foja 8 .

43. Instrucciones y reglamento generales de actividades de la Campaña Antivariolosa, 1935-1945. AHSSA. Fondo: Salubridad Pública; Sección: Epidemiología; caja 60 , exp. 8 .

44. Vacunación antivariolosa en los templos; 1922. AHSSA. Fondo: Salubridad Pública; Sección: Inspección de Vacuna, caja 3, exp. 22, 1922, 3 fojas.

45. Relación de las oficinas de vacuna; 1922. AHSSA. Fondo: Salubridad Pública; Sección: Inspección de Vacuna, caja 3, exp. 23, 1922, 1 foja.

46. Informe del servicio extraordinario de vacunación antivariolosa, practicada en la Delegación de Guadalupe Hidalgo, durante el mes de diciembre de 1931; 1931. AHSSA. Fondo: Salubridad Pública; Sección: Inspección de Vacuna, caja 4, expediente 16, 1932, 10 fojas, foja 3.

47. Las brigadas de vacunadores del Departamento de Salubridad. El Universal 1923; jun 24. p. 1; 7.

48. Las brigadas de vacunadores del Departamento de Salubridad. El Universal 1923, jun 23. p. 7.

49. Comunicado de la Delegación Sanitaria de Guadalupe Hidalgo sobre el impedimiento que impuso la directora de la Escuela Presidente Sarmiento a la aplicación de la vacuna contra la viruela en los alumnos; 1932.

50. Petición del médico de oficina de vacuna "Dr. Balmis"; 1926.

51. Carrillo AM. Salud pública y poder en México durante el Cardenismo, 1934-1940. DYNAMIS - Acta Hisp Med Sci Hist Illus 2005; 25:145-178.

52. Castro JF. La erradicación de la viruela en México. Gaceta Médica de México 1997; 133(12):99-106.

53. Informe de las actividades concretas desarrolladas durante el año comprendido entre el $1^{\circ}$ de septiembre de 1935 y el 10 de septiembre de 1936. Salubridad 1936; 6(1):75.

54. Castro JF. La erradicación de la viruela en México. Gaceta Médica de México 1977; 113(12):102.

55. Chavarria VF. Informe mensual de labores de la brigada de educación higiénica correspondiente al mes de agosto de 1949. (mimeo).

56. Una epidemia de variolosis. El Informador 1947; 3 ago. p. 20.

57. Linchamiento. El Porvenir 1948; 9 jun. p. 11.

58. Informe de labores antivariolosas desarrolladas del 26 de mayo al 25 de junio de 1949 por el personal de la brigada número 2 en la cuenca de Tepalcatepec, Michoacán; 1949. AHSSA. Fondo: Secretaría de Salubridad y Asistencia; Sección: Subsecretaría de Salubridad y Asistencia, v. 33, exp. 9.

59. Bustamante ME. Vigesimoquinto aniversario de la erradicación de la viruela en México. Gaceta Médica de México 1977; 113(12):55.

Artigo apresentado em 13/4/2010

Aprovado em 11/6/2010

Versão final apresentada em 17/6/2010 